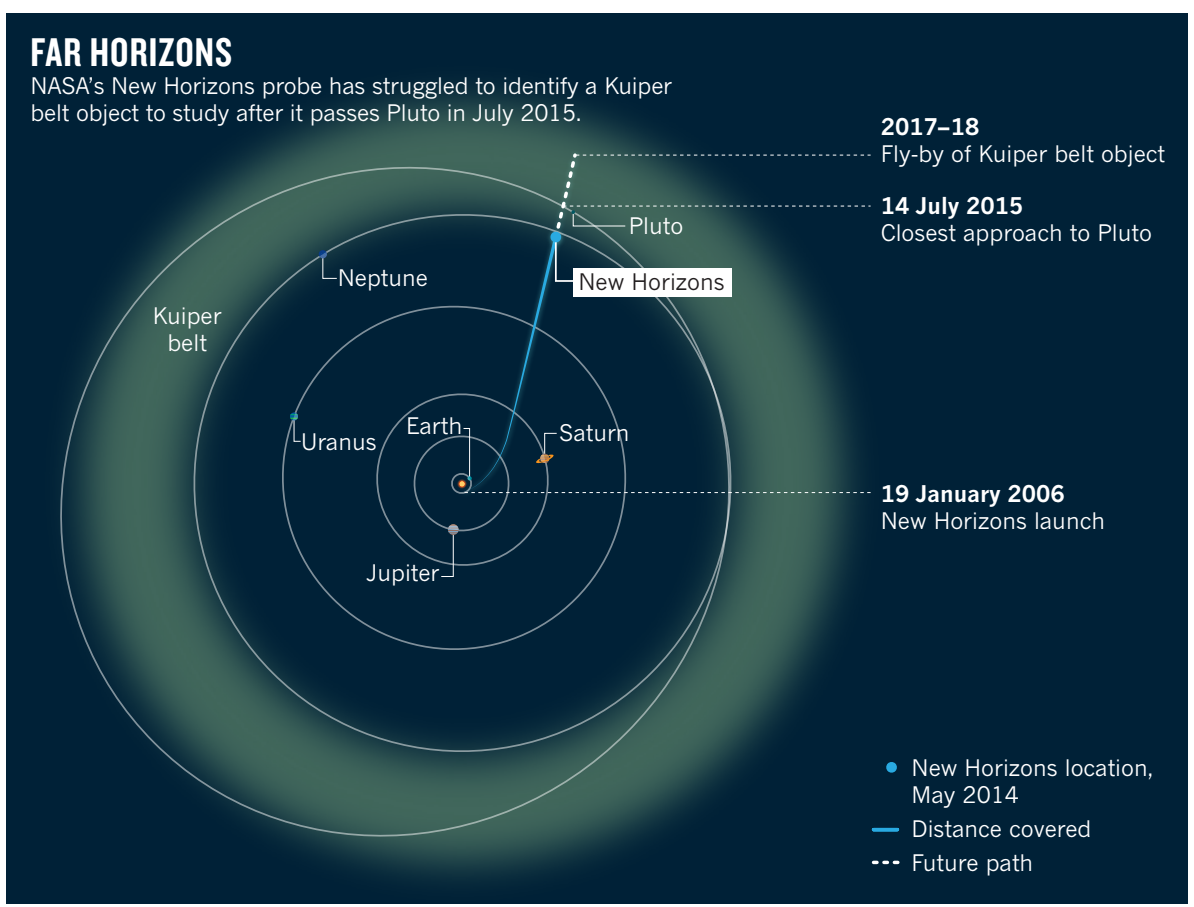

the past couple of years, astronomers have discovered that there are fewer dim KBOs than was extrapolated on the basis of the number of bright ones. "There just aren't as many faint ones," says Grundy — and faint, faraway KBOs are what New Horizons must detect.

For a mission that has been carefully planned for many years, the failure to find a KBO target is striking. But Sykes is not alarmed. "That should have been in the calculus, but it really wouldn't have changed their ground-based campaign," he says.

The team has another eight nights with Subaru in late June and July, and hopes to win some more time in August. It has also applied for extra observing time with Magellan in October. Even if conditions are near perfect, the chances of snaring a KBO from the ground this year are less than $40 \%$. With the requested Hubble time, those chances soar to greater than $90 \%$.

Without Hubble, it might still be possible to identify a KBO target from the ground early next year. But that would complicate the mission, because New Horizons would have to wait for longer after visiting Pluto to fire its engines. In that case, the spacecraft would need to execute a sharper turn than team scientists would like to reach the correct trajectory.

In the worst-case scenario, New Horizons would be forced to observe a KBO from far away. Several possible long-distance targets have already been spotted (S. D. Benecchi et al. Icarus http://doi.org/ssn; 2014). Even with its puny 21-centimetre telescope, New Horizons would get a better glimpse of a distant $\mathrm{KBO}$ than the 2.4-metre Hubble can manage from an Earth orbit.

Not that the team has yet given up hope of a close KBO target. "If we can find one," says Grundy, "we will happily take it." -

\title{
Submersible loss hits research
}

\author{
But scientists remain positive about the future of deep-sea exploration despite \\ disintegration of unique US Nereus craft.
}

\section{BY DANIEL CRESSEY}

$\mathrm{R}$ esearchers have lost access to a huge and unexplored area of the ocean after one of the world's most advanced submersibles blew apart 10 kilometres underwater during a deep-sea expedition. The loss of Nereus, operated by the US Woods Hole Oceanographic Institution (WHOI), leaves ongoing and future projects high and dry. But scientists who study the bottom of the ocean have told Nature that their research programmes will continue, and that the design of a potential successor to Nereus is already under way.

Nereus was in the Kermadec Trench in the Pacific Ocean on 9 May when its five camera feeds suddenly went blank. Researchers aboard the RV Thomas G. Thompson were unable to contact the US\$8-million craft. They learned its fate when pieces of its hull floated to the surface.

"It was a horrible feeling - of denial and disbelief," says Tim Shank, a biologist at the
WHOI in Massachusetts and chief scientist on the expedition.

It is likely that one of the ceramic vessels used to encase components on Nereus collapsed under the water pressure, leading to an implosive chain reaction.

Shank's expedition was part of a US National Science Foundation (NSF) programme to investigate the hadal zone. This area of the ocean, in deep-sea trenches between 6,000 and 11,000 metres down, is one of the least explored regions on Earth.

Researchers have long dismissed the idea that the area is a 'dead zone'. For example, on its first deep dive in May 2009, Nereus discovered a new species of anemone in the deepest part of the ocean, Challenger Deep in the Pacific's Mariana Trench. But systematic exploration has been lacking, leading in 2011 to the creation of the NSF project, an international collaboration called the Hadal Ecosystem Studies (HADES) programme. It aims to determine the composition and distribution of hadal species, and the role of hadal pressures, food supply and trench topography on community structure.

During the final dives of Shank's expedition, the first for HADES, researchers were measuring the metabolic rates of invertebrates such as sea cucumbers. This was done by using Nereus to place the creatures in a respirometer mounted on a separate platform. The work, which began in April, would have provided crucial data on whether trenches act as carbon sinks, and would have enabled researchers to start unpicking the food webs of the deep ocean.

"The loss of Nereus is an absolute tragedy for hadal research. We no longer have the capability to explore the lower two-thirds of our ocean with a remotely operated vehicle," Shank told Nature.

Access to the deep is an ongoing challenge because only a few specialized vessels can reach this part of the ocean. The WHOI's Alvin 


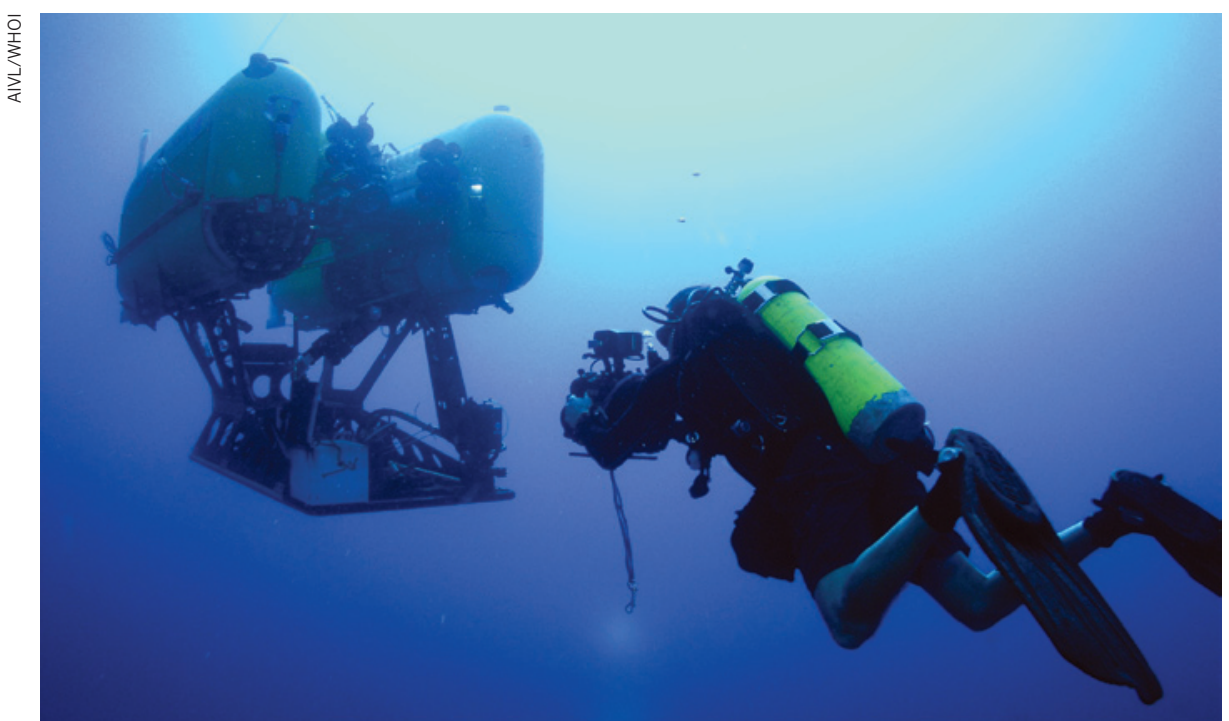

The Nereus submersible is thought to have been lost after extreme water pressure led to an implosion.

vehicle, which is crewed rather than operated remotely, can dive to only about 4,000 metres. China, Japan, France and Russia have crewed submersibles that can reach depths of 6,000-7,000 metres (see 'Into the abyss'). Several remotely operated or autonomous research robots are also in use, but few can withstand the enormous pressures of the hadal zone.

The only other operational vessels to rival Nereus for depth range are the DEEPSEA CHALLENGER craft used by film director James Cameron for his 2012 voyage, and Japan's ABISMO vehicle, which has reached 10,250 metres. But DEEPSEA CHALLENGER is not a scientific craft, and ABISMO's equipment is not as advanced as Nereus's was.

Deep-sea data collection is still possible without Nereus. For example, Shank and his team have been able to continue some of their work by deploying other equipment, such as water and sediment samplers. Other affected expeditions are also making alternative arrangements. Nereus was due to take part in another HADES mission later this year, to explore the Mariana Trench, and expedition chief scientist Jeffrey Drazen of the University of Hawaii at Manoa says that the mission will still go ahead. Its aim is to collect animals, images and sediments from the hadal zone, and some of the work can be conducted using baited traps and instrument platforms, called landers, that sink to the bottom, says Drazen. His team is also investigating deploying a towed camera system. Nereus gave real-time access and allowed scientists to point cameras directly at objects of interest and to collect samples on the fly, rather than throwing equipment off the side of their ship and hoping for the best.

There is a glimmer of hope for deep-sea exploration with submersibles. Even before the demise of Nereus, the WHOI was in discussions with the Schmidt Ocean Institute in Palo Alto, California, about constructing another 'full-ocean capable' vehicle. The collaboration is in a preliminary design phase. Scientists could be using the vehicle by mid2016, says Victor Zykov, the Schmidt's director of research.

The WHOI is in contact with its insurers over Nereus. A payout could be used to build two of the next-generation vehicles envisaged by Schmidt, instead of one.

As the Nereus disaster shows, having a second submersible is a good idea, says WHOI engineer Andy Bowen, an expert in remotely operated vehicles who was lead scientist on the design of Nereus. "This is a very forceful reminder of how difficult it is to work in the ocean in general, and at the extremes even more so," he says.
However, these are static technologies.

\section{\begin{tabular}{l|l} 
& TOP NEWS
\end{tabular}}

MORE ONLINE
- Palaeoamerican skeleton is studied in underwater cave. go.nature.com/55tfch

- Gravitational-waves finding under scrutiny. go.nature.com/omv8ih

- Solar wind could trigger lightning. go.nature.com/ufjv19

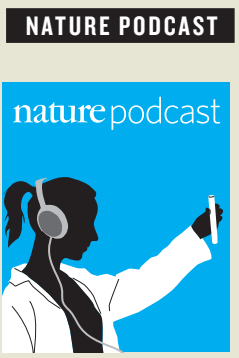

Babies with three parents, and the sea gooseberry's nervous system. nature.com/ nature/podcast

\section{INTO THE ABYSS}

The world's fleet of deep-sea submersibles has dwindled further with the loss of Nereus.

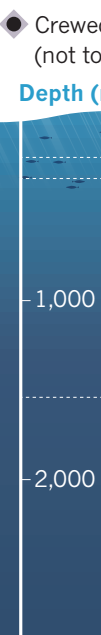

$-3,000$

Maximum dive by mamma

Little sunlight

Deepest scuba dive.

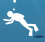

No sunlight

Estimated depth of Deepwater Horizon oil-well leak

2,000
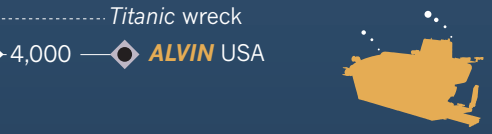

$-5,000$

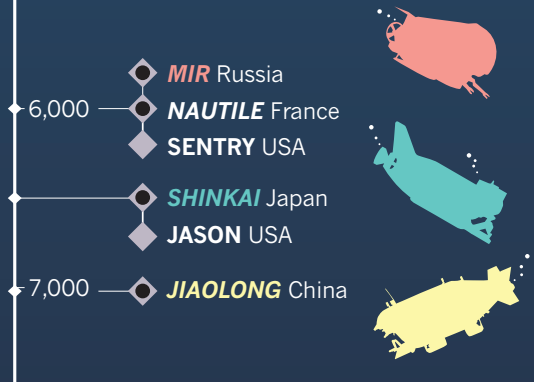

Deepest fish seen

$-8,000$

Puerto Rico Trench. Deepest point in the Atlantic Ocean

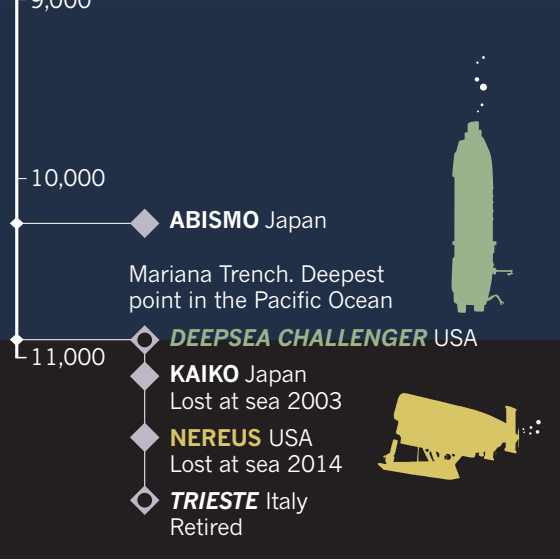

